\title{
Histopathological changes in the liver after allogeneic bone marrow transplantation
}

\author{
JP SLOANE, 1 MJG FARTHING, ${ }^{3}$ AND RL POWLES ${ }^{2}$ \\ From the ${ }^{1}$ Department of Histopathology, and ${ }^{2}$ Leukaemia Unit, The Royal Marsden Hospital, Sutton, \\ Surrey, and ${ }^{3}$ Department of Gastroenterology, St Bartholomew's Hospital, London EC1, UK
}

SUMMARY Postmortem and surgical specimens of liver from 20 patients who had undergone allogeneic bone marrow transplantation for a variety of disorders were examined. The lesions fell into five major categories: bile duct atypia often associated with portal tract fibrosis (8 cases), veno-occlusive disease ( 2 cases), small foci of non-zonal hepatocyte necrosis ( 3 cases), opportunistic infections ( 3 cases), and a miscellaneous group of non-specific abnormalities. Our findings, in conjunction with those in experimental animals, point strongly to the bile duct lesion being a specific manifestation of graft versus host disease (GvHD). Veno-occlusive disease has also been reported recently as a possible manifestation of a graft versus host reaction and, although both our patients with this lesion had evidence of GvHD in the skin and gastrointestinal tract, both had also received irradiation and 6-thioguanine, and these may have been responsible. The foci of hepatocyte necrosis could not be attributed to GvHD with any confidence as the lesion was of only minor severity, infrequent, highly non-specific in appearance and, furthermore, did not correlate well with the presence of bile duct lesions. The absence of specific clinical and biochemical findings in human hepatic GvHD stresses the need for biopsy to make a firm diagnosis. However, the patchy distribution of the bile duct lesion and its absence from the needle biopsies examined in this study suggest possible sampling problems, and further study is necessary to assess its value.

In addition to its obvious therapeutic benefits, the technique of bone marrow transplantation has also introduced a whole new spectrum of iatrogenic human pathology resulting from graft versus host disease (GvHD) or from the side-effects of the cytotoxic and immunosuppressive agents that have to be administered. GvHD is characterised clinically by anorexia, diarrhoea, hepatic functional abnormalities, and a desquamative skin rash. Histological changes are observed predominantly in the skin, gastrointestinal tract, and liver, and there have been a number of detailed studies on the morphological features of GvHD in man as well as in a number of species of experimental animals. In man, however, interest has centred largely on changes in the skin, which is readily accessible and in which biopsy is safe. Furthermore, the opportunity for macroscopic inspection considerably reduces sampling problems. Consequently, the liver has received much less attention, and the aim of the present study

Received for publication 3 October 1979 is to describe the lesions observed in the livers of patients who have received bone marrow allografts and to determine their possible significance.

\section{Patients, material, and methods}

The livers of all patients who had undergone bone marrow transplantation at The Royal Marsden Hospital and on whom percutaneous needle biopsy or postmortem material was available were examined histologically by conventional light microscopy. Formalin-fixed paraffin-embedded sections were stained with haematoxylin and eosin, haematoxylin van Gieson, Perls' method for haemosiderin, and modified Glees method for reticulin. ${ }^{1}$ Gram stains were used for the identification of bacteria and Grocott's methenamine silver stain for fungi.

Patient details are summarised in the Table. The age range was 3-37 with an average of 19 years. The primary diagnosis was aplastic anaemia (AA) in five patients, acute myeloid leukaemia (AML) in eight, acute lymphoblastic leukaemia (ALL) in five, neuroblastoma in one, and granulocytic sarcoma in one. 
Table Summary of major clinical features and hepatic histopathological abnormalities in 20 patients given allogeneic bone marrow

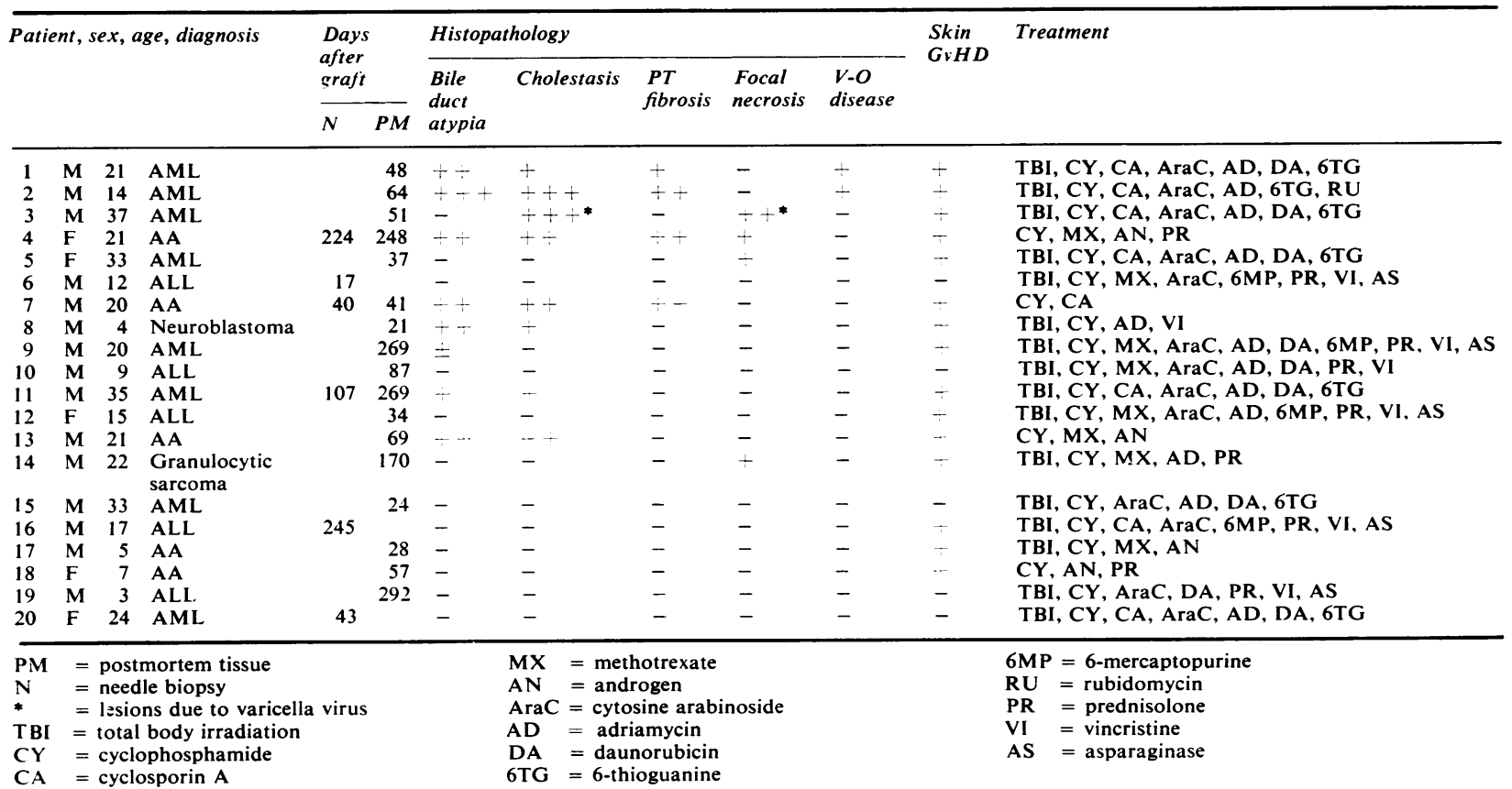

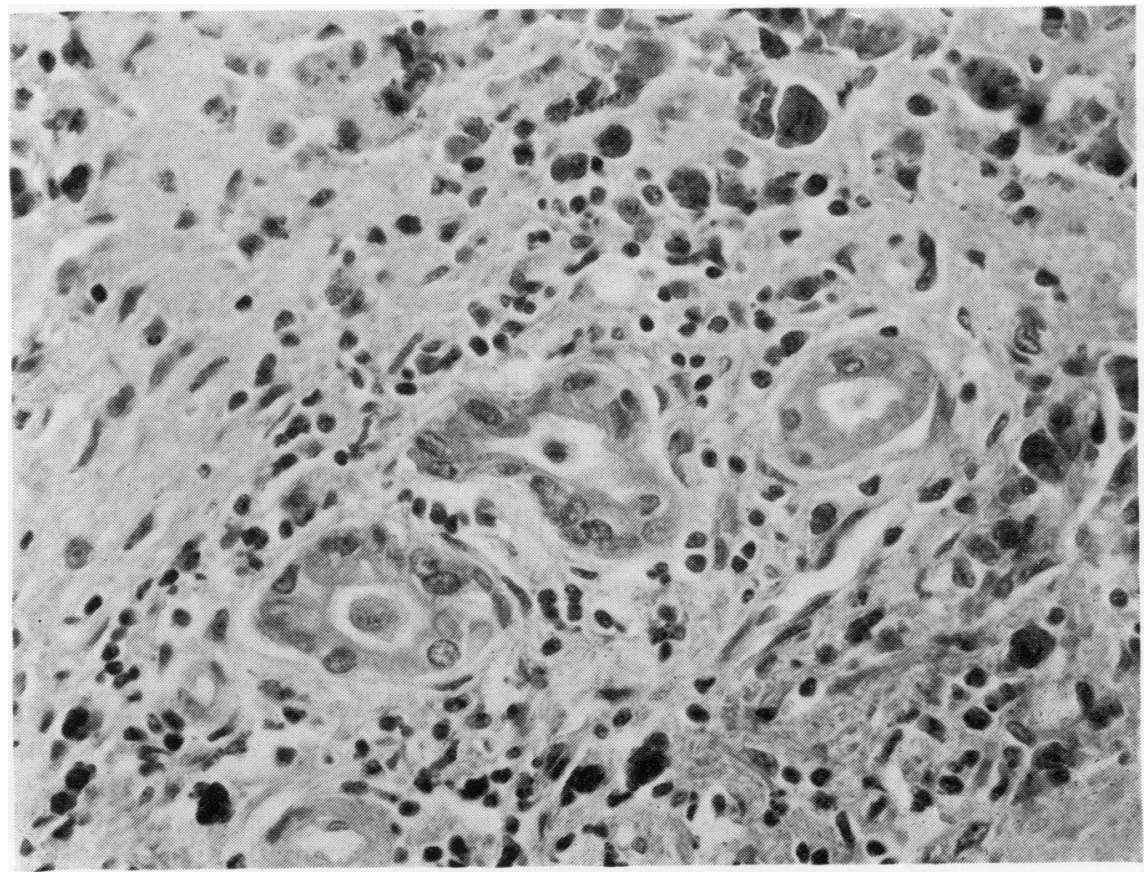

Fig. 1 Group of three small bile ducts showing epithelial atypia and surrounded by a few chronic inflammatory cells and several large, irregular deposits of haemosiderin. (Haematoxylin and eosin $\times 400)$. 


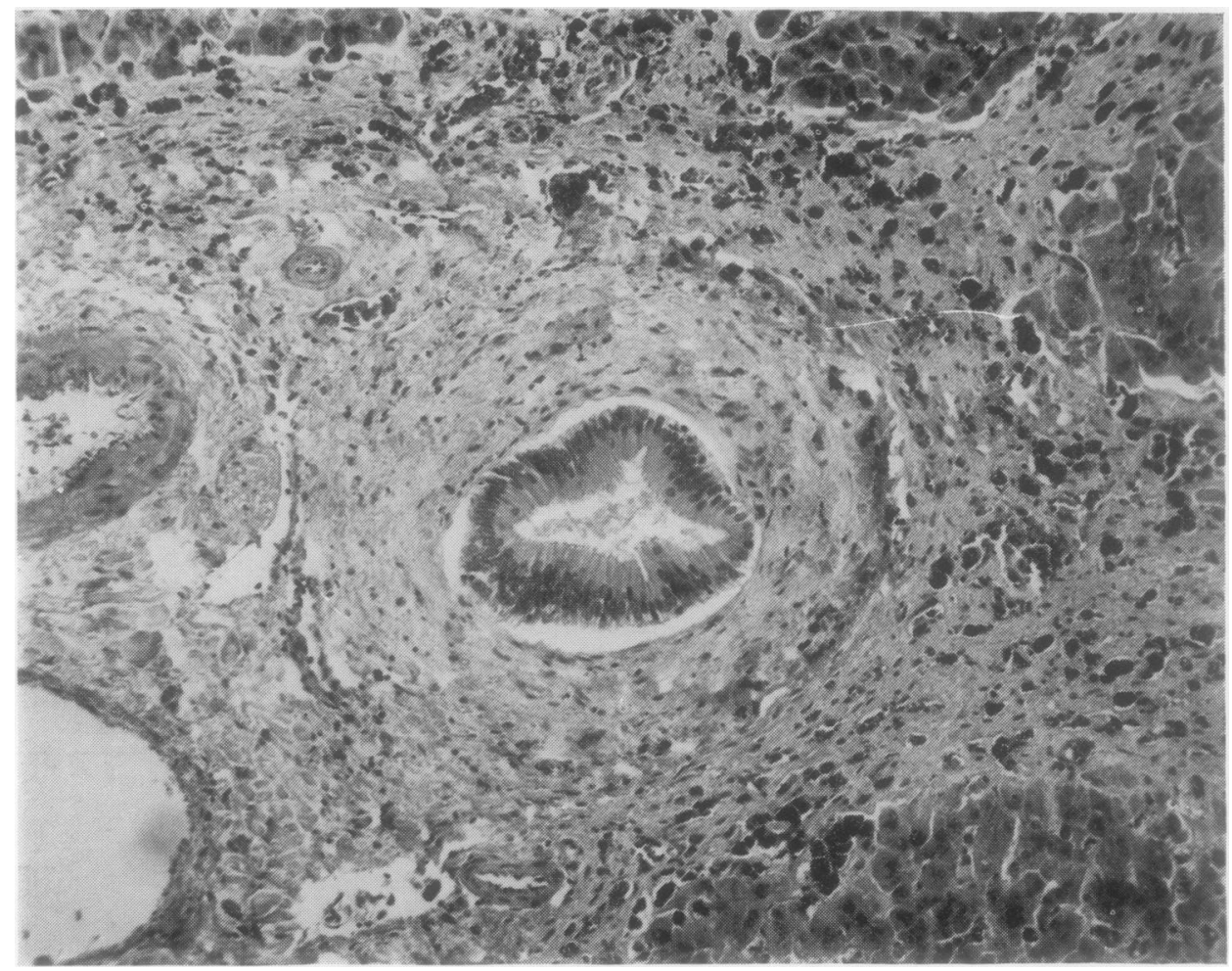

Fig. 2 Larger bile duct from same case as in Fig. 1, showing nuclear multilayering.

( $H$ and $E \times 120$ ).

Pretransplant immunosuppression was achieved by total body irradiation of $1000 \mathrm{r}$ and cyclophosphamide $(60 \mathrm{mg} / \mathrm{kg})$ in 15 patients, and by cyclophosphamide alone in five. Other drugs administered are summarised in the Table. Fifteen patients had clinical or histological evidence of GvHD in the skin, and nine of these also had evidence of gastrointestinal GvHD.

Postmortem tissue was available for study in 17 patients and needle biopsies in six. Needle biopsy and postmortem material was available in patients 4,7 , and 11 , and biopsy preceded death by intervals of 24,1 , and 162 days respectively. The time interval between grafting and biopsy or death is indicated in the Table and varied between 17 and 292 days. Patients 4, 6, and 18 required a second transplant, and in these cases the time interval is measured from the time of the second graft.

\section{Results}

The livers of 20 patients were available for study and exhibited the following abnormalities:

ATYPIA OF BILE DUCT EPITHELIUM

This was observed in eight cases and was largely confined to the small ducts (Fig. 1) which exhibited an in egular outline and a lumen which was often poorly defined and sometimes contained fragments of necrotic material. The ductal epithelial cells showed nuclear pleomorphism and hyperchromatism and an increased nucleocytoplasmic ratio. A few cells even appeared anucleate. The larger ducts were much less frequently involved and showed changes of lesser severity which usually took the form of nuclear multilayering (Fig. 2) or cytoplasmic mucin accumulation. Lymphocytic infiltration was occasionally seen around abnormal ductules but was always very minor, and infiltration of the epithelium itself was only very rarely observed. The lesion was associated with cholestasis in all but the mildest example (case 9), and four of the eight patients also exhibited a mild to moderate degree of portal tract fibrosis with extension of fibrous septa of varying length in the surrounding parenchyma (Fig. 3). 


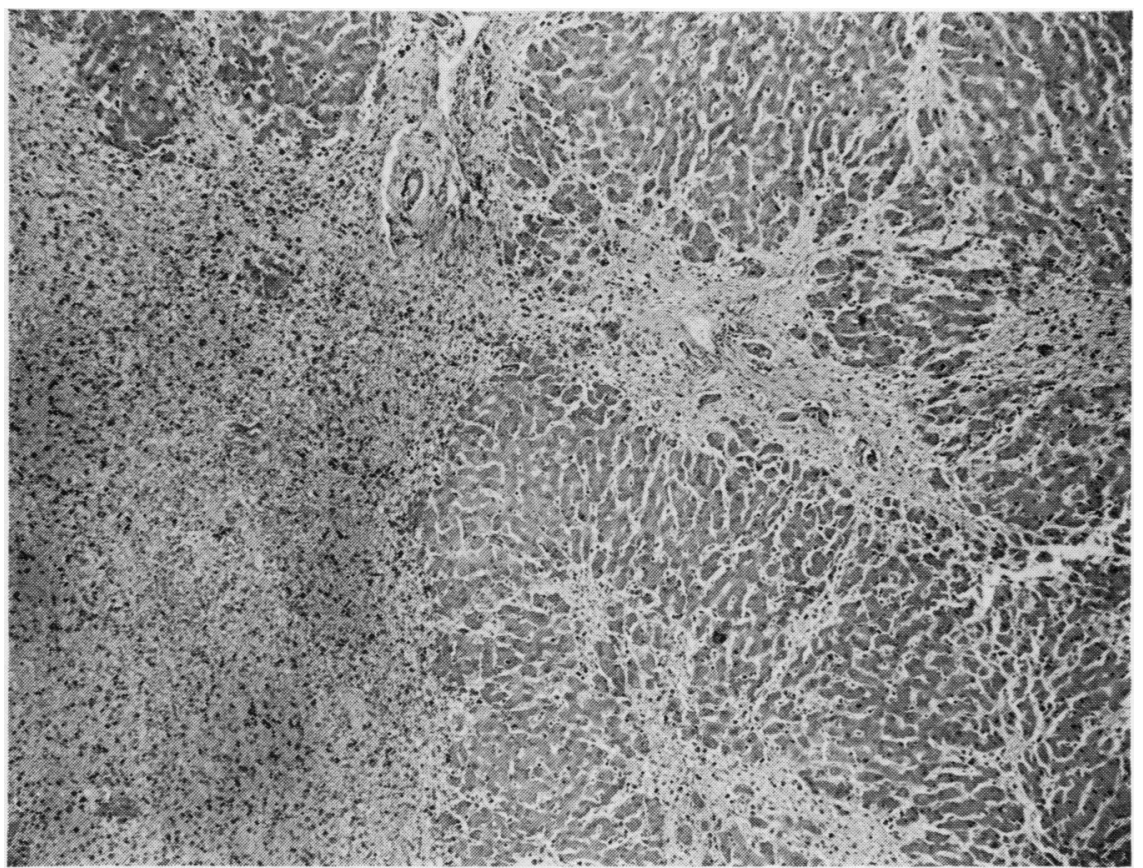

Fig. 3 Liver showing portal tract fibrosis with septum formation (right) and centrilobular congestion and necrosis due to veno-occlusive disease (left). ( $H$ and $E \times 40)$.

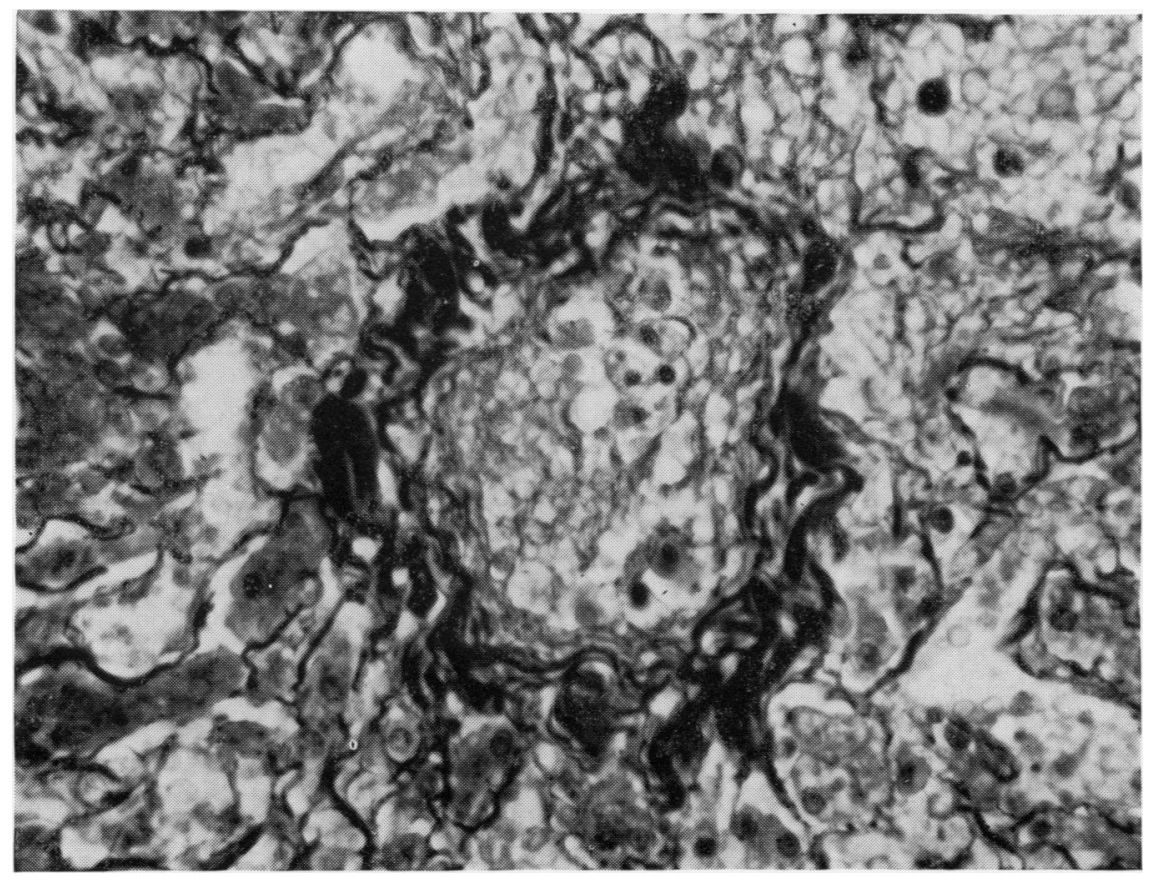

Fig. 4 Central vein occluded by fine meshwork of reticulin fibres. Taken from same case as in Fig. 3. (Reticulin $\times$ 400). 


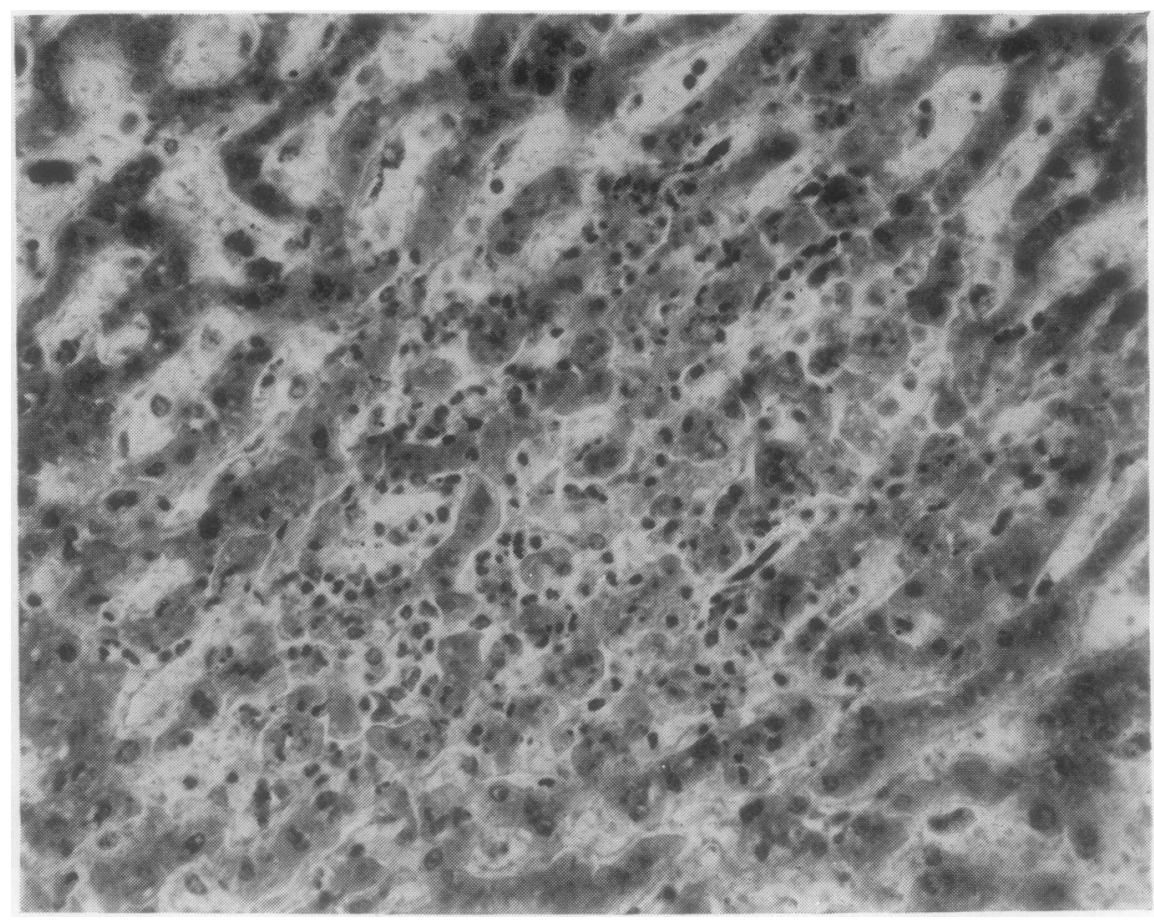

Fig. 5 Small focus of hepatocyte degeneration and necrosis accompanied by neutrophil and chronic inflammatory cell infiltration. ( $H$ and $E \times 250$ ).

VENO-OCCLUSIVE DISEASE

Two patients exhibited extensive, severe centrilobular sinusoidal dilatation and congestion associated with hepatocyte loss and atrophy (Fig. 3). Central veins in these areas showed partial or complete occlusion by a fine intraluminal meshwork of reticulin fibres (Fig. 4). These changes were far more pronounced in the right lobe than in the left. Evidence of minor degrees of veno-occlusion was sought in reticulin stains of the remaining livers but none was found.

\section{FOCAL NECROSIS (Fig. 5)}

This was seen in three of the 20 patients and took the form of infrequent, tiny, non-zonal foci of hepatocyte necrosis measuring approximately $1 \mathrm{~mm}$ across and associated with a minor degree of acute and chronic inflammatory cell infiltration. A careful search for organisms proved to be negative in all cases. One patient with this lesion also exhibited bile duct atypia.

\section{OPPORTUNISTIC INFECTIONS}

Three patients exhibited evidence of hepatic opportunistic infection. One patient had developed a characteristic varicella rash just before death, and postmortem examination revealed the presence of intranuclear viral inclusions in hepatocytes and bile duct epithelial cells as well as in the epidermis. Hepatocyte necrosis and cholestasis were both prominent. Another liver contained numerous small (approximately $2 \mathrm{~mm}$ ) abscesses containing Candida sp., and a third exhibited numerous colonies of Gram-positive bacilli within sinusoids and blood vessels. Precise identification of this organism was not made as cultures could not be established.

\section{MISCELLANEOUS LESIONS}

Moderate to severe siderosis was observed in all the livers examined and was presumably related to previous blood transfusions. A mild to moderate degree of fatty change was seen in six livers, and small foci of extramedullary haemopoiesis were present in three. Minor abnormalities in reticulin pattern were observed in 16 livers and these took the form of an increase in numbers and density of sinusoidal reticulin fibres, particularly in central venous areas. Such changes have been observed after irradiation $^{2}$ and cytotoxic drugs. ${ }^{3}$

\section{Discussion}

A variety of lesions has been described in the livers 
of patients who have undergone bone marrow transplantation. Krüger et al., ${ }^{4}$ in a study of eight patients, described portal tract lymphocytic infiltration which tended to be arranged around bile ducts and which also showed focal invasion of hepatic cords associated with necrosis of occasional hepatocytes. Portal tract fibrosis was also noted as well as fatty change, siderosis, and, in one patient, centrilobular congestion and necrosis. Kersey et al. ${ }^{5}$ examined six patients and also found periportal infiltrates and fatty change. A recent study by Berk et al. ${ }^{6}$ of 22 patients who had died after bone marrow transplantation revealed chronic inflammatory cell infiltration and fibrosis of portal tracts, hepatocyte necrosis of varying degrees and distribution, ground glass hepatocytes, opportunistic infections, and veno-occlusive disease. Bile duct lesions were not described in any of these studies but were reported by Slavin and Santos ${ }^{7}$ and later stressed by Lerner et al., ${ }^{8}$ who stated that hepatic GvHD is reflected by degeneration and necrosis of small bile duct epithelium and hepatocytes. Furthermore, as they considered the bile duct lesion to be a consistent feature of hepatic GvHD, a grading system based on the percentage of bile ducts involved was proposed. Woodruff et al. ${ }^{9}$ confirmed the presence of bile duct lesions in patients with GvHD but were more reserved about their significance, stating that they were invariably associated with viral infections of the liver or elsewhere.

It is evident from these studies that the morphological changes occurring in the livers of patients with GvHD are of a varied and often non-specific nature, and in particular it is often difficult to determine the relative importance of secondary infection, drugs, irradiation, and GvHD in their pathogenesis. However, there are two major points of evidence arising from the present study which indicate that the bile duct lesion is a manifestation of hepatic GvHD. Firstly, all eight patients with the lesion had evidence of GvHD in the skin and none of the five patients without skin GvHD exhibited it. Secondly, it could not be related to any mode of therapy, only five of the eight receiving radiotherapy, four cyclosporin A, four cytosine arabinoside, five adriamycin, three daunorubicin, three 6-thioguanine, two androgens, two prednisolone, two vincristine, one 6-mercaptopurine, one asparaginase, and one rubidomycin. Although all patients had received cyclophosphamide, a drug known to cause cellular atypia particularly in the bladder, we have been unable to find any record of such bile duct lesions among the particularly well documented side-effects of this drug.

There is also strong experimental evidence. De Vries et al. ${ }^{10}$ transfused allogeneic marrow into irradiated monkeys and noted swelling, increased cytoplasmic eosinophilia, nuclear pyknosis, and occasional mitoses in small bile duct epithelium. Swollen, fragmented bile duct epithelial cells were also noted in allografted rhesus monkeys by Woodruff et al. ${ }^{11}$ eight days after transplantation. Such lesions were not recorded in any of the three control groups which comprised normal untreated monkeys, irradiated non-transfused monkeys, and irradiated animals transfused with autologous marrow. Sale et al. ${ }^{12}$ gave allogeneic marrow to irradiated dogs and noticed necrosis and severe atypia of bile duct epithelial cells after 10-14 days, and again these lesions were not observed in irradiated controls which were either ungrafted or had received autologous marrow.

The absence of lymphocytes from the lesions is a puzzling observation, but the presence of portal tract fibrosis in four cases indicates a fairly advanced state of a process which might also have been modified considerably by immunosuppressive treatment. Bile duct lesions were observed in the present study between 21 and 224 days after grafting, and in all those patients in whom postmortem skin was also available for study, there was little or no evidence of residual active disease. A transient aggressor lymphocyte reaction resulting in irreversible bile duct epithelial damage is clearly a plausible explanation, although humoral factors may also be involved as Tsoi et al. ${ }^{13}$ have demonstrated deposits of IgM and $\mathrm{C}_{3}$ at the dermo-epidermal junction in the skins of many patients with GvHD. A similar immunohistochemical study might well be of value in elucidating the pathogenesis of the liver lesions.

Although viruses are known to produce bile duct lesions, ${ }^{14} 15$ they are unlikely to be responsible for the bile duct atypia in bone marrow allografted patients. The absence of the lesion in irradiated non-transfused experimental animals is against direct recipient infection, and its absence in individuals receiving syngeneic marrow ${ }^{16}$ is against infection transfused from the donor. Viral inclusions were observed in none of our patients with bile duct atypia.

The significance of the veno-occlusive disease is uncertain. Berk et al. ${ }^{6}$ found veno-occlusive disease in seven out of 11 livers of patients who had died after bone marrow transplantation, and as all seven had evidence of GvHD elsewhere, they suggested that it might be a hitherto unrecognised component of the same process. Veno-occlusive disease has also been described, however, after irradiation ${ }^{17}$ and after the administration of various cytotoxic and immunosuppressive drugs such as urethane, ${ }^{18}$ azothiaprine, ${ }^{19}$ and 6-thioguanine. ${ }^{3}$ Both our patients had GvHD but both had also received irradiation 
and 6-thioguanine. Although veno-occlusive disease is not usually reported at doses of less than about 35001 , such doses would be fractionated, and pretransplant irradiation, although only $1000 \mathrm{r}$, is given as a single dose. Furthermore, cytotoxic drugs could potentiate any irradiation effect. It may be significant that the veno-occlusive changes were more pronounced in the right than the left lobe as the right lobe would receive a greater dose of irradiation because of its more superficial location.

The small foci of necrosis are much more difficult to assess. Although focal necrosis has been attributed to GvHD and we have no evidence to implicate any specific drug, infection, or irradiation, it was, on the other hand, an infrequent lesion of minor severity which did not correlate well with the presence of bile duct atypia. The lesion represents a very non-specific manifestation of liver damage, and it may be significant that animal experiments on GvHD have occasionally revealed foci of hepatocyte necrosis in control animals. ${ }^{12}$

Finally, although our findings demonstrate the value of histological examination of the liver in the diagnosis of GvHD, the role of needle biopsy needs more evaluation as the absence of the bile duct lesion in any of the six needle biopsy specimens examined and the patchy distribution of the changes suggest that there may be significant sampling problems.

We are indebted to Mrs Diana Mitchell and the staff of the histopathology laboratory of the Royal Marsden Hospital and Institute of Cancer Research for technical assistance, and to Mrs Vivianne Williams for typing the manuscript. MJGF is supported by the Wellcome Trust.

\section{References}

${ }^{1}$ Chadwin CG. A method for the demonstration of reticulin fibres using a modified Glees silver solution. J Sci Technol 1969;15:56.

${ }^{2}$ Lewin K, Millis RR. Human radiation hepatitis. Arch Pathol 1973;96:21-6.

${ }^{3}$ Griner PF, Elbadawi A, Packman CH. Veno-occlusive disease of the liver after chemotherapy of acute leukemia. Ann Int Med 1976;85:578-82.

4 Krüger GRF, Berard CW, De Lellis RA, et al. Graftversus-host disease: Morphological variation and differential diagnosis in 8 cases of HL-A matched bone marrow transplantation. Am J Pathol 1971; 63:179-97.

${ }^{5}$ Kersey JH, Meuwissen HJ, Good RA. Graft versus host reactions following transplantation of allogeneic haematopoietic cells. Hum Pathol 1971 ;2:389-402.

${ }^{6}$ Berk PD, Popper H, Krüger GRF, Decter J, Herzig G, Graw RG, Jr. Veno-occlusive disease of the liver after allogeneic bone marrow transplantation. Ann Int Med 1979;90:158-64.

'Slavin RE, Santos GW. The graft versus host reaction in man after bone marrow transplantation: pathology pathogenesis, clinical features and implication. Clin Immunol Immunopathol 1973;1:472-98.

${ }^{8}$ Lerner KG, Kao GF, Storb R, Buckner CD, Clift RA, Thomas ED. Histopathology of graft versus host reaction (GvHR) in human recipients of marrow from HL-A matched sibling donors. Transplant Proc 1974;6:367-71.

${ }^{9}$ Woodruff JM, Hansen JA, Good RA, Santos GW, Slavin RE. The pathology of the graft-versus-host reaction (GvHR) in adults receiving bone marrow transplants. Transplant Proc 1976;8:675-84.

${ }^{10}$ de Vries MJ, Crouch BG, Van Putten LM, Van Bekkum DW. Pathologic changes in irradiated monkeys treated with bone marrow. J Natl Cancer Inst $1961 ; 27: 67-97$.

11 Woodruff JM, Eltringham JR, Casey HW. Early secondary disease in the Rhesus monkey. I. A comparative histopathologic study. Lab Invest 1969; 20:499-511.

${ }^{12}$ Sale GE, Storb R, Kolb H. Histopathology of hepatic acute graft-versus-host disease in the dog. Transplantation 1978;26:103-6.

${ }^{13}$ Tsoi MS, Storb R, Jones E, et al. Deposition of IgM and complement at the dermo-epidermal junction in acute and chronic cutaneous graft-versus-host disease in man. $J$ Immunol 1978;120:1485-92.

${ }^{14}$ Mosley JW, Galambos JT. Viral hepatitis. In: Schiff L, ed. Diseases of the Liver, 4th Edn. Philadelphia: JB Lippincott, 1975:540.

${ }^{15}$ Wigger HJ, Blanc WA. Fatal hepatic and bronchial necrosis in adenovirus infection with thymic alymphoplasia. $N$ Engl J Med 1966;275:870-4.

${ }^{16}$ Weiden PL, Flournoy N, Thomas ED, et al. Antileukemic effect of graft-versus-host disease in human recipients of allogeneic-marrow grafts. N Engl J Med 1979;300:1068-73.

${ }^{17}$ Reed GB, Jr, Cox AJ, Jr. The human liver after radiation injury. Am J Pathol 1966;48:597-611.

${ }^{18}$ Ohler RL, Houghton JD, Moloney WC. Urethane toxicity: report of a case of hepatic necrosis apparently due to urethane. $N$ Engl J Med 1950: 243:984-8.

${ }^{19}$ Marubbio AT, Danielson B. Hepatic veno-occlusive disease in a renal transplant patient receiving azathioprine. Gastroenterology 1975;69:739-43.

Requests for reprints to: Dr JP Sloane, Department of Histopathology, The Royal Marsden Hospital, Sutton, Surrey, UK. 